\title{
Leveraging Rhetoric for Improved \\ Communication of Science: A Scientist's \\ Perspective
}

\section{Jamie Vernon}

ORISE Fellow, U.S. Department of Energy

Washington, D.C. USA

Poroi 10,1 (J anuary 2014)

Keywords: rhetoric, rhetoric of science, collaboration, National Science Foundation, science communication, interdisciplinarity, broader impacts

\section{A Scientist's Perspective on Rhetoric in Science Outreach}

\begin{abstract}
"Must not the art of rhetoric, taken as a whole, be a kind of influencing of the mind by means of words, not only in courts of law and other public gatherings, but in private places also?"

261a-261b

$\sim$ Socrates, Phaedrus,
\end{abstract}

Leveraging rhetoric for improved science communication requires an appreciation on the part of scientists of the rhetorician's expertise. In this regard, I consider the task of persuading scientists like myself to recognize our need for rhetorical practitioners as minimally different from that of the scientist who him or herself wishes to persuade the public to more enthusiastically adopt an evidence-based lifestyle. Indeed, this obliges the rhetorician to employ her own persuasive skills when engaging the scientific community in the pursuit of collaborations.

The "Rhetoric \& Outreach" panel at the 2013 ARST preconference represents a compelling step in this direction. My participation as a representative of the scientific community allowed me to think critically about the role of rhetoricians in science and science outreach. The accomplished "rhetors" on the 
panel presented myriad examples of value rhetoric offers the modern science communication enterprise. Kenny Walker's work on the communication of uncertainties is particularly timely given the current need for real risk management in communities responding to the impacts of climate change.

Walker's (2012) analysis of Rachel Carson's use of uncertainty to make her arguments was revelatory. After inviting him to write a post for the Dot Earth Blog describing his paper, Andrew Revkin added a follow-up quote from Walker that punctuates his findings:

If you can be accurate yet still use uncertainty to frame the impact, you're not only trustworthy, you're interesting, and you effectively shape the terms of debate. We've all got to stop ignoring uncertainty, and instead learn to manage it. Fifty years later, I think that's one of the primary lessons of "Silent Spring" (Revkin, 2012).

Walker's work clearly demonstrates the insight a skilled rhetorician can bring to understanding how to construct or deconstruct an effective rhetorical argument. I have rarely observed this proficiency among my scientific colleagues. Leveraging the expertise of the rhetorician could enhance the scientist's communication strategy.

As demonstrated by the other panelists, rhetoricians are not limited to analyzing other's arguments. An important point made by Caroline Druschke that "communication researchers are capable of posing research questions, rather than just delivering the results of someone else's research" resonated with my own experience as a scientist trying to establish a research niche. I also appreciate this concept within the context of recent advisements from the National Academy of Sciences Sackler Colloquium on "The Science of Science Communication." Baruch Fischoff and Dietram Scheufele summarized the meeting by stating, "communication is viewed as a two-way process, in which scientists must listen as well as speak", meaning "communication of science is held to the same evidentiary standards as the science being communicated" (Scheufele, 2013).

Given Druschke's purview, it seems to me that rhetoric as a discipline has already plowed through many of the questions scientists are just now discovering. Why should scientists reinvent the wheel when rhetoricians have been tackling these problems for years? The key question dogging the panel was whether the 
rhetorician's skill set aligns well with the needs of scientists. Based on the presentations from the preconference panelists, I believe rhetoricians are uniquely equipped to advance science communication and should be highly valued by scientists who wish to engage the public, but they must be deployed appropriately.

As stated in the opening quote, rhetoric is the art of influencing the mind in order to change public and private behaviors. The scientific community has chosen to invest in public engagement on a large-scale through a variety of efforts, as described in J ean Goodwin's introduction. The decision to commit public resources to this work has been attributed to numerous goals including a need to improve teaching, training, and learning, a desire to diversify the scientific workforce and an aspiration to increase public understanding of science. Based on my observations, rhetoric as an effective tool for conveying information and influencing behaviors can support each of these goals.

Others in the scientific community are motivated to engage the public as a response to a separate set of concerns--increased competition for scientific research funds, the realization of stagnating or declining public scientific literacy, a materialization of "anti-science" policies, active opposition to science standards in state and local boards of education, and many others. These perceived threats have resulted in a coordinated effort of formal and informal activities designed to positively influence the public perception of science. Again, the rhetorician's skill set seems to be honed to address this objective.

In many cases, my colleagues and those in other scientific disciplines have taken it upon themselves to initiate science outreach through writing, blogging, working with citizen scientists, and engaging with elected officials. Some are proving less effective than others, in part due to what appears to be rhetorical deficiencies. Perhaps confidence gained through scientific success leads some scientist communicators to feel they are equipped to generate persuasive content.

All too often, though, the material produced by well-intentioned scientists pulls from the false assumption that information dissemination is sufficient for persuasion. This notion, identified as the "deficit model", positions the scientist as the enlightened expert whose mere conveyance of "facts" influences others' behavior. The notable absence of evidence to support this claim invites the rhetorician to lend her expertise.

The challenge faced by the rhetorician is to identify the communication space that best leverages her knowledge and aligns 
with the scientist or institution's strategic goals. While the escalation of interest in science communication may be partly a response to concerns about a perceived lack of appreciation of science, in actuality, this is rarely the goal laid out by agencies that fund science outreach. The National Science Foundation's (NSF) "Broader Impacts" Merit Review Criteria ${ }^{1}$ are the oft-cited justification for science outreach by federally funded researchers. NSF Grant Reviewers are asked to evaluate all proposals against two criteria:

Intellectual Merit: The Intellectual Merit criterion encompasses the potential to advance knowledge; and

Broader Impacts: The Broader Impacts criterion encompasses the potential to benefit society and contribute to the achievement of specific, desired societal outcomes.

Although the "Broader Impacts" criterion is general enough to be subject to interpretation, it does not appear to provide a mandate to persuade publics. Previous broader impacts criteria were focused on increasing the efficacy of scientific research in order to advance public interests. Interpreting the current criteria to include explicit persuasion goals would be a significant change. Indeed, recent news of a White House initiative to create a "Behavioral Insights Team" aimed at influencing how Americans react to certain policy reforms has met with by a fair amount of criticism. For these reasons, I was skeptical that the rhetorician's talent for performing research that develops more persuasive communication would be well suited or, even, appropriate for broader impacts work.

However, as demonstrated by panelist, Sara Parks, an "embedded rhetor" can inform and improve the external engagement activities of a national program designed to stimulate competitive research. Whether Parks' performance exceeds that of other scientific or communications experts is yet unknown. However, Parks' success with EPSCoR has demonstrated the value a trained rhetorician can bring to these types of programs.

Further complicating the scientists' decision to rely on trained rhetoricians are recent trends in science communication. At

${ }^{1}$ http:// www.nsf.gov/bfa/dias/policy/merit_review/overview.pdf 
a National Academy of Science (NAS) Workshop on Sustainable Infrastructures for Life Science Communication, Rick Borchelt, Director of Communications and Public Affairs for the U.S. Department of Energy's Office of Science, expressed concern that "the science communication model has moved from a PIO model to a marketing and institutional advancement model." Similarly troubling is the fact that media coverage of science has gravitated toward the communication of breakthroughs rather than the more contingent advancement of scientific knowledge (Cascais, 2005). These developments potentially undermine public appreciation for science by distorting public expectations as well as failing to satisfy the basic aims of the NSF broader impacts criteria. In addition, they seem to marginalize the need for complex and contextual communications, which is one of many attributes rhetoricians can deliver.

The putative value rhetoricians offer science communication calls for additional evidence, which will be enhanced by strategic deployment of practitioners. In my opinion, a growing catalog of success stories such as those presented on this panel should influence scientists not only to appreciate rhetoric but also to approach and adopt practitioners to help achieve their objectives. The emerging emphasis on treating science communication as a scientific endeavor bodes well for rhetoricians. During the NAS Life Science Communication Workshop, J ack Schultz, Director of the University of Missouri School of J ournalism's HHMI-funded program on communicating science to the public, delivered a message to institutions, "Don't do science communication alone." He encouraged them to bring in journalists, artists, and communications experts. This, I believe, is also an invitation to rhetoricians.

A savvy rhetorician will understand the complex science communication landscape and identify integration points that match her talents with appropriate outreach initiatives. The skilled rhetorical scholar will evaluate communication projects in order to recognize prospects for advancing the project goals while simultaneously providing research opportunities. As a community, rhetoricians should engage with initiatives designed to improve communication training for STEM graduate students, such as the COMPASS \#GradSciComm initiative (2013) and the AAAS Emerging Leaders in Science \& Society (ELISS) program (2013). Continuing to build a strong portfolio of success is the most effective way rhetoricians will solidify their role in the science communication enterprise. 
In her opening comments for the panel, J ean Goodwin stated, "Scientists want to communicate. We [rhetoricians] want to help." Indeed, it seems to me that scientists should accept their offer.

Copyright ( 2014 J amie Vernon

\section{References}

AAAS eliss-overview. (2013) ELISS website. Retrieved from http:// www.aaas.org/ page/ eliss-overview

Cascais, A.F. (2005). The rhetoric of breakthroughs in the communication of science. The Pantaeto Forum, 17. Retrieved from http:// www.pantaneto.co.uk/issue17/ cascais.htm

Compassblogs. (2013). \#GradSciComm Archive. Retrieved from http:// compassblogs.org/gradscicomm/

Fischhoff, B. and D.A. Scheufele. (2013). The science of science communication. Proceedings of the National Academy of Sciences. 110 Suppl. 3. Retrieved from http:// www.pnas.org/content/110/Supplement 3/14031.full

Revkin, Andy. (2012). How Rachel Carson spurred chemical concerns by highlighting uncertainty. Dot Earth (Sept. 27). Retrieved from http:// dotearth.blogs.nytimes.com/ 2012/ 09/27/ how-rachelcarson-spurred-chemical-controls-by-highlightinguncertainty/? $\mathrm{r}=0$

Walker, K. and L. Walsh. (2012). "No one yet knows what the ultimate consequences may be": How Rachel Carson transformed scientific uncertainty into a site for public participation in Silent Spring. J ournal of Business \& Technical Communication, 26(1), 3-34. 